\title{
O RAP DA FELICIDADE E O RAP DO SILVA: MÚSICA DE PROTESTO?
}

\section{THE RAP DA FELICIDADE AND RAP DO SILVA: PROTEST MUSIC?}

\author{
Vitor Israel Trindade de Souza \\ Universidade de São Paulo \\ vitordatrindade@usp.br
}

\section{Resumo}

Este texto se configura como um ensaio onde abordo elementos da música de protesto negra, especialmente, o gênero conhecido como funk carioca, procurando estabelecer relações com outras abordagens históricas da música de protesto negra no Brasil, principalmente, as produzidas durante os anos de chumbo da ditadura militar brasileira. A metodologia utilizada para a construção deste texto foi a revisão bibliográfica e a análise de diferentes músicas, consideradas enquanto música de protesto, em especial, Rap da Felicidade (CIDINHO; DOCA, 2007) e Rap do Silva (MC Marcinho, 2007), que se estruturaram como ponto de partida para os processos reflexivos. Além dessa abordagem, utilizei, como processo metodológico, minhas memórias pessoais, inseridas dentro de uma narrativa autoetnográfica, conforme proposto por Santos (2017). Como resultados do processo reflexivo, ancorado por Ikeda (20 18), Nascimento (2002), Nascimento (2017), Vianna (1988) e Brown (2018), é possível apontar que a música de protesto negra, ainda hoje, é recebida com desconfiança pela sociedade e que, de maneira geral, os mecanismos mercadológicos e midiáticos procuram descontextualizá-la, configurando a criação de uma figura "não negra" para protagonizar esses estilos, transformando-os em formas que podem ser consideradas cultas e interessantes, ao mesmo tempo em que denigre (Ainda que denegrir signifique em sua literalidade "tornar negro") suas características originais.

Palavras-chave: Música de protesto negra; Funk carioca; Cultura afro-brasileira. 


\begin{abstract}
This text is an essay where I approach elements of black protest music, especially the genre known as funk carioca, seeking to establish relationships with other historical approaches to black protest music in Brazil, mainly those produced during the lead years of the Brazilian military dictatorship. The methodology used for the construction of this text was the bibliographic review and the analysis of different songs, considered as protest music, in particular, Rap da Felicidade (CIDINHO; DOCA, 2007) and Rap do Silva (MC Marcinho, 2007), which structured themselves as a starting point for reflective processes. In addition to this approach, I used, as a methodological process, my personal memories, inserted within an autoetnographic narrative, as proposed by Santos (2017). As a result of a reflective process anchored by lkeda (2018), Nascimento (2002), Nascimento (2017), Vianna (1988) and Brown (2018), it is possible to point out that black protest music, even today, is received with suspicion by society and, in general, the marketing and media mechanisms seek to decontextualize it, configuring the creation of a "non-black" figure to lead these styles, transforming them into forms that can be considered cultured and interesting, at the same time, where denigrating (Although denigrating literally means "turning black") its original characteristics.
\end{abstract}

Keywords: Protest black music; Funk Carioca; Cultura Afro-brasileira. 


\section{Prólogo}

"Contam os mais velhos, que em tempos remotos, somente Ossaim, tinha o poder e o conhecimento das folhas. Ossaim guardava o segredo de todas as curas numa grande cabaça pendurada no galho mais alto de uma árvore. Lá ficavam os segredos de todas as folhas e de todas as curas. 0 seu poder absoluto estava garantido. Um dia Yansan chamou Xango e eles conversaram sobre o poder de Ossaim. Por que não compartilhar o que era imprescindivel para o bemestar de todos? Marcaram hora e lugar para uma conversa com Ossaim. O encontro aconteceu pontualmente e a concentração foi bem embaixo da árvore do conhecimento das folhas.

Yansan que possui a energia dos ventos, iniciou uma dança embaixo da árvore que guardava o segredo de Ossaim. Ela foi girando cada vez mais rápido para chamar atenção para interesse de todos. Ela dançou girando com tanta força que toda natureza foi se transformando. Yansan produziu tanto vento que a cabaça do segredo começou a balançar até se chocar com o tronco e se partir, deixando cair as folhas que foram colhidas por todos e todas que passaram, e assim, todos passaram a ter o direito, indistintamente, de usar folhas que curam e alimentam."

(Narrativa do falar africano)'

I Oficina Nacional de Elaboração de Políticas Públicas de Cultura Para os Povos Tradicionais de Terreiro - Relatório Final, 2012, p.7)

http://rubi.casarvibarbosa.gov.br/bitstream/20.500.1 1997/6739/1/432.\%200ficina_ Politicas_Publicas_Cultura_Terreiro_20 12.pdf (acesso em 03/06/2020). 


\section{Introdução}

Neste trabalho apresento um ensaio baseado em elementos da música de protesto negra, elementos que apresentam traços em comum desde o processo de escravidão e deportação dos povos africanos, trazidos de suas terras natais para o que se conhece hoje como território brasileiro. O objetivo desse ensaio é apresentar alguns desses elementos, estabelecendo relações de proximidade ou afastamento, principalmente, entre a música de protesto realizada durante os anos de chumbo da ditadura militar no Brasil (1964-1985) e os movimentos do funk, abordando algumas de suas origens e algumas das suas manifestações atuais. Se ancora em autores como Nascimento (2002), Nascimento (2008), Ikeda (2008), Vianna (1988) e Brown (2018), procurando traçar um paralelo com minhas observações pessoais, enquanto músico inserido dentro dos contextos de algumas das culturas populares afro-brasileiras.

A metodologia utilizada para a realização desse trabalho foi a revisão da literatura e da de referenciais musicais disponibilizados nas redes digitais, além de minhas memórias pessoais, utilizadas neste trabalho, quase de maneira autoetnográfica. Essa metodologia está estruturada em ideias de Santos (2017), que propõe o estabelecimento de narrativas pessoais como elemento comparativo de situações vivenciadas por processos coletivos. Segundo Santos (2017), a origem da palavra autoetonografia "nos remete a um tipo de fazer específico por sua forma de proceder, ou seja, refere-se à maneira de construir um relato ("escrever"), sob um grupo de pertença ("um povo"), a partir de "si mesmo" (da ótica daquele que escreve) (SANTOS, 2017, p. 218)

A motivação para a elaboração deste trabalho se deu através do meu contato pessoal com o texto Música, Política e Ideologia: Algumas Considerações (IKEDA,200 I)². Ikeda (200 I) aponta vários aspectos da música de protesto e dos efeitos dessa música na sociedade como um todo. A fim de realizar minha própria reflexão sobre o tema, tomo como referência a música que, segundo meu ponto de vista, acredito

2 Comunicação apresentada no V Simpósio Latino-Americano de Musicologia, Fundação Cultural de Curitiba,

Curitiba - Paraná, 18 a 21 de janeiro de 2001, baseada na tese: Alberto T. IKEDA, "Música Política: imanência

do social", Escola de Comunicações e Artes, Universidade de São Paulo (USP), 1995 (Nota do Autor). 
seja a atual música de protesto: o gênero conhecido como funk cario$\mathrm{Ca}^{3}$, a parte renegada da cultura hip hop ${ }^{4}$. Considero que tal gênero é fundamental enquanto linguagem, no diálogo da população jovem e adulta com as instituições estabelecidas: governo, mídia e status quo.

$\bigcirc$ funk carioca, através da sua poesia escrachada e sem pudor agride a "sociedade brasileira defensora de falsas morais", mas que, ao mesmo tempo, traz consigo uma permissividade aberta ao feminicídio, a homofobia e outros atos de total desrespeito ao ser humano. $\bigcirc$ funk carioca não se constitui apenas como um grito anárquico dos adolescentes, ele se alinha a todo um grupo de jovens e adultos, entre 12 e 35 anos, que constroem e vivenciam esse gênero musical. Sua poética reflete a filosofia e o modo de vida destas pessoas. Tendo em vista minha concepção de que dentro dos processos musicais, diferentes aspectos se interconectam, procuro, nos próximos parágrafos, adentrar em aspectos geográficos do surgimento e estabelecimento do funk carioca, além de questões relacionadas ao gênero e raça que são fundamentos deste trabalho. Além do já mencionado, as músicas pertencentes a este gênero, intituladas Rap da Felicidade, lançada no álbum Tropa de Elite de autoria dos músicos Cidinho e Doca (2007) e Rap do Silva, de autoria de MC Marcinho (2007), cantada pelo Mc Bob Rum, se constituirão como guias para as discussões apresentadas pelo trabalho. Proponho através desse texto realizar uma reflexão sobre a apropriação do funk pela cultura hegemônica, que procura "embranquecê-lo" com o intuito de condiciona-lo a padrões estéticos, culturais e sociais considerados "aceitáveis" pela sociedade de consumo, desconectando-o de suas fontes de origem, na tentativa de esvaziar seu poder político e sua força enquanto música de protesto negra.

Dentro do contexto apresentado, considero que minha história pessoal se configura como elemento desencadeador do processo reflexivo, inserido dentro das perspectivas anteriormente apontadas. Em

$3 \bigcirc$ Funk Carioca é parte da cultura Hip Hop que se instalou no Rio de Janeiro na década de 80, a partir das batidas trazidas pelo DJ Marlboro que trouxe para o RAP (Ritmo e Poesia) os grooves do Miami Bass. Tal estilo musical se adaptou facilmente as formas de rimar que faziam parte das marchinhas de carnaval. Diferentemente do Funk derivado da Soul Music, assentado na bateria baixo e metais, o Funk Carioca tem seu groove baseado nos beats do DJ, e até de elementos trazidos pelas baterias das escolas de samba.

4 Hip Hop é o nome do movimento que diminui as guerras de gangue que ocorrem entre os bairros estadunidenses. Essa diminuição ocorre através dos seus cinco elementos: o Grafite, os Bboys e Bgirls (dançarinos), o DJ (disc jockey), os MCs (Mestre de Cerimônias) e o Conhecimento. 
diálogo com as ideias de RIVEIRA (2019), parto do princípio que, muitas vezes, essas tradições e elementos culturais foram (e continuam a ser) apagados durante o processo de invasão das terras dos povos originários do Brasil e da posterior ocupação pelos povos africanos, realizada por meio dos processos escravagistas e pelos povos europeus, via imigração. De igual maneira, essas tradições e culturas vem sendo descartadas dos processos acadêmicos, que desconhecem, e quando conhecem, muitas vezes, as menosprezam, desconsiderando-as como forma de produção, comunicação e transformação do conhecimento humano (RIVEIRA, 2019). Com base na crença de que é fundamental o desvelamento dessas histórias para que possam ser travados diálogos entre o autor e os leitores, a fim de construir novas reflexões conjuntas apresento, nos próximos parágrafos, parte da minha trajetória, enquanto pessoa-músico-pesquisador.

Sou oriundo de uma família de artistas ligados as tradições das culturas populares. Fui iniciado por eles na arte, na dança e na música. Posteriormente, assumi nas práticas do Cambomblé a função de Ogan Alabê Omoloiê, que é o cargo de Ogan que rege os outros cargos de uma Casa de Candomblé. Paralelamente, desenvolvo minha atuação enquanto músico, compositor e professor de música e cultura popular afrobrasileira. Além da minha abordagem a aprendizagem de música através de ambientes considerados, academicamente, como informais ou não-formais, sou graduado em Música Popular pela Faculdade Instituto Tecnológico de Osasco (FITO) e mestrando na ECA-USP, no curso de Musicologia.

Atuo como arte educador e palestrante em diversos contextos, incluindo instituições fora do Brasil, como a Landesmusikakademie (Academia Federal de Música), sediada em Berlin, Alemanha, sempre durante o mês de setembro, no Festival Samba Syndrom. Também na Alemanha desenvolvi um trabalho, durante cinco anos, na Musikschule Schoneberg (Escola Municipal de Música do Distrito de Schoneberg), além de ter atuado como decente no Groove Zentrum fur Perkussion, que se configura como uma escola privada. No momento como presidente do Teatro Popular Solano Trindade, fundado por Raquel Trindade (19362018). No teatro é promovido, entre outras atividades, o curso Identidade Cultural Afro-brasileira (ICAB). Esse curso oferece ferramentas aos professores da Rede Pública de Embu das Artes, através de um convênio realizado com a prefeitura dessa cidade. 
Tendo em vista o exposto, cabe destacar que utilizo, durante este texto, uma confluência de linguagens expressivas. Algumas vezes abordo as perspectivas e reflexões sugeridas utilizando-me de linguagem acadêmica, conforme a tradição eurocêntrica. Outras vezes, utilizo as linguagens populares, marcada por expressões próprias dessas culturas, onde muito de minhas vivências se localizam. Acredito que essas diferentes maneiras de utilização das linguagens escritas não são autoexcludentes. Sob meu ponto de vista, se configuram como uma abordagem estruturada em processos coletivos, que visam o estabelecimento de um conhecimento permeado por influências da ambas as propostas. Entre essas influências, uma representa uma minoria hegemônica, e outra uma maioria que, quase sempre, vem sendo discriminada e privada do acesso aos seus direitos mais elementares, entre eles, o aceso a academia.

Neste texto, essas abordagens se complementam sob dois enfoques: a proposta de comunicação estabelecida pelo texto, é direcionada, principalmente, à inclusão da minoria hegemônica dentro de um processo de produção de conhecimento, distinto dos adotados pela academia; o texto se configura como uma abordagem a ser publicada por mecanismos inseridos dentro da tradição acadêmica eurocêntrica, e assim, necessita adotar, algumas de suas estratégias e configurações. Meu próprio ingresso nas instituições acadêmicas, voltadas a propostas de pesquisa, se estabelece como um elemento de diálogo entre as duas abordagens. Sendo assim, este texto faz parte desse processo de aproximação e estabelecimento de diálogos possiveis, configurando-se como parte do processo coletivo anteriormente citado.

\section{Breve contextualização}

Com o fortalecimento de uma politica de extrema direita, que assumiu a direção do Brasil desde o início de 2019, com propostas que lembram atos de esquizofrenia, ou no mínimo, um quadro surrealista, a população brasileira com posicionamento político ligado às ideologias de esquerda tem se levantado em protesto, como forma de enfrentamento e em defesa dos direitos dos cidadãos. Entre os atos indiscriminados dos dirigentes que vem assumindo o poder político nos últimos tempos, podemos destacar, por exemplo, a campanha a favor do golpe, denominado Impeachment, que fortaleceu a escalada da "bancada evangélica" e da "bancada da bala" ao poder, a proposta 
da diminuição ou extinção das verbas destinadas as áreas de Ciências Humanas das Universidades Federais e outras aberrações políticas de igual teor. Começamos, então, a "re-ouvir" no rádio músicas que fizeram sucesso nos anos sessenta, como Caminhando (Ceraldo Vandré) e Apesar de Você (Chico Buarque) que foram sucesso nos anos de chumbo da ditadura militar no Brasil (1964-1985).

Essas reflexões e considerações sobre o contexto em que se insere a realidade brasileira, me fazem elaborar as questões que movem este texto: neste momento em que o governo foi eleito democraticamente (apesar de por meio pouco lícitos) as cantigas de guerra e enfrentamento dos anos sessenta possuem a mesma eficiência? Mesmo depois das conquistas pós "Diretas já", "Negro é lindo" e "Lula lá"? Já não é hora de ouvir outras vozes? Vozes diferentes das cantadas pelos jovens revolucionários da União Nacional dos Estudantes (UNE) e partidos de esquerda daquela época?

Acredito que os anos de 2018 e 2019 estão sendo abalados por muitas mudanças em todo o mundo, inclusive no Brasil. No período em que me dediquei a escrever este texto, dois grandes atos de violência e agressividade, com autoria de grupos extremistas de direita, assombraram a população do Brasil e da Nova Zelândia. No Brasil, na cidade de Suzano, interior de São Paulo, dois jovens armados entraram em sua escola e assassinaram vários outros alunos que ali estudavam, durante o período das aulas. Na Nova Zelândia, homens entraram em uma mesquita, e assim como o ocorrido em São Paulo, dispararam tiros indiscriminadamente, levando à morte quarenta pessoas que faziam suas orações. Ações distantes geograficamente, mas que, possivelmente, seguem uma mesma proposta: demonstrar ódio aos que não aderem aos pensamentos extremistas do "White Power", e seus inimigos pessoais, que são (ou somos) todos os "não brancos" ou "não cristão.

Em contrapartida, em outro movimento político na capital paulistana, ações de jovens da periferia propõem discussões acerca dos problemas das, e nas suas comunidades. Através de textos diretos e ações que culminam em "saraus", "slams", "batalhas"7 e em movimentos,

5 Encontros de Poesia que acontecem na Periferia das Capitais Brasileiras, principalmente desde os anos 90.

6 Batalha de Poesias.

7 Batalhas de Free Style, improvisação sobre as batidas de Hip Hop. 
como o incentivo a permacultura ${ }^{8}$, a alimentação orgânica e a economia solidária9, essas ações se tornaram um "forte". Buscam defender as pessoas que frequentam as "comunidades de bairro" 10 , as ONCS, os bailes e bares de bairros periféricos de São Paulo, como por exemplo, Capão Redondo, Heliópolis, Brasilândia e São Mateus. Através de suas ações, protegem a população que habita esses bairros, das instituições que permanecem hegemônicas na forma de governar e educar. Instituições, essas, que promovem a exclusão do povo, ao invés de vê-lo como o foco principal para o desenvolvimento nacional.

As redes sociais vêm se constituindo, cada vez mais, como a principal ferramenta dos "periféricos"I". Através dela, esses jovens, excluídos pelos dirigentes do país, criam seus eventos culturais e políticos; formam conexões que se delineiam com suas linguagens próprias; apresentam formas de literatura, cinema e música; promovem reuniões políticas, de afirmação das suas várias tribos ${ }^{12}$. Com isso, o periférico não precisa mais se deslocar com tanta frequência aos centros urbanos atrás de cultura e lazer. Ao contrário, constrói espaços culturais dentro de, e para seu próprio círculo, cria locais de trabalho cada vez mais próximos de seus espaços de moradia.

Porém, esse movimento de utilização das redes sociais, que trouxe independência para os moradores de fora dos centros urbanos, trouxe também a eleição de um presidente totalmente inapto para o papel de "regente" do país, que em seus discursos de campanha gritava pela moral e bons costumes. Nesses discursos, os bailes de periferia, a música

\footnotetext{
8 Permacultura foi desenvolvida na década de 70 por Bill Mollison e David Holmgren na Tasmânia, em resposta ao sistema industrial e agráola da época. Eles organizaram a cultura ancestral, a sabedoria moderna e a tradicional e criaram a palavra. Permacultura tem como base a ecologia e é um instrumento utilizado para a criação de sistemas humanos sustentáveis.

9 termo economia de solidariedade, apareceu pela primeira vez no Brasil num texto de Razeto em 1993 que o concebia como uma formulação teórica de nível científico elaborada a partir e para dar conta de conjuntos significativos de experibencias econômicas (...) que compartilham alguns traços constituitivos e essenciais de solidariedade, mutualismo, cooperação e auto-gestão comunitária, que definem uma racionalidade especial, diferente de outras racionalidades econômicas.

10 Ponto de Encontro para as discussões da sociedade que vive nas comunidades.

II Palavra utilizada para referir-se as pessoas que se consideram ativistas pela melhoria na periferia, ou mesmo o morador comum da periferia.

12 Grupo de pessoas consideradas "tribos dos tempos modernos", grupos que criam sua moda e sua própria filosofia.
} 
alta dos "paredões"13 e a proposta de sexualidade livre 14 dos adolescentes dos bairros pobres eram alguns dos seus principais alvos.

A propaganda fascista ${ }^{15}$ do atual governo, veiculada, principalmente, pela mesma mídia social da qual se beneficiam os jovens da periferia para fortalecer seus movimentos, ofereceu, falsamente, durante a campanha eleitoral, uma proposta de mudança na política em prol da segurança do "cidadão de bem". Leia-se: pessoas brancas da classe média, média alta e alta. Essa veiculação culminou na eleição de um presidente de extrema direita e com propósitos visivelmente fascistas de destruição e desmonte do país. Se pode observar essa tendência quando se assiste a entrega aos americanos da Base de Alcântara, no Maranhão, o afrouxamento da lei contra os agrotóxicos, os cortes de verbas dirigidas às Universidades Públicas, a liberação do comércio e fabricação de armas de fogo e, ainda, outros impropérios, que se não fossem extremamente trágicos, representariam uma atitude infantil.

Quem não está contemplado na proposta de segurança desse governo passa, então, a ser vítima do segurador. Assim, os bairros menos privilegiados e seus habitantes, na maioria das vezes, pobres e, consequentemente, afrodescendentes estão cotidianamente na mira das rondas ostensivas do aparato de proteção dos mais abastados. Contra a conjuntura vigente, a periferia escolheu, como seus heróis, - "Gangsta"16 Mano Brown, o machista Mc Livinho, a "esculachada" Jojo Todinho, as "poderosas" Annita e Ludimila e a feminista, poética e musicalmente falando, Karol Conká, entre outros defensores.

Também se observa a presença de uma "rapaziada mais bonitinha", mais chique, que "curte" Jorge Vercilo, o Rappa e outras estrelas da Nova MPB. Em seus discursos e conversas, entre uma e outra cerveja, incluem o ódio ao funk ${ }^{17}$ ou a outros gêneros mais populares, como o

13 Aparelhagem de som, em que caixas empilhadas formam verdadeiras paredes sonoras. 14 A ideia de sexualidade livre é diferente da ideia proposta pelos hippies nos anos 60 , defende o direito a escolha de gênero na relação sexual.

15 Movimento político autoritário que surgiu na ltália após a primeira guerra mundial. $\bigcirc$ governo de Jair Bolsonaro trouxe várias propostas que se assemelham a um projeto fascista, conseguindo com isso esse título do povo brasileiro.

16 Palavra utilizada para referir-se aos jovens que se comportam e vestem roupas que remetem aos gangsters que povoam o Harlem, bairro nova-iorquino.

17 Funk Carioca. 
pagode ${ }^{18}$ e o sertanejo 19. Na mesma roda, ambos os grupos "curtem" Pablo Vittar e Liniker, cantando o mundo Queer ${ }^{20}$, representado política e corretamente por Jean Willis e pela deputada eleita Érica Malunguinho, primeira negra e transexual eleita para o Parlamento Brasileiro.

\title{
-"Qual é que é mano"?
}

A questão da sexualidade (ou da escolha sexual) é a referência maior do jovem dos dias de hoje em suas propostas poéticas, seus protestos e suas discussões políticas. Essa escolha se reflete, de forma epistemológica, na relação desses jovens com a música e com a musicalidade. Quero dizer que, assim como na década de setenta se protestava através da poesia de Chico Buarque e Geraldo Vandré, como uma forma de resistência ao governo da ditadura militar, hoje em dia as composições falam do direito de se ser o que se quiser ser, "trazendo numa mesma carroça", os direitos das mulheres, os direitos dos homossexuais, e, em contrapartida, os deveres dos homens. Até que se prove o contrário, no conceito geral da atualidade, esses detém todos os direitos que a sociedade oferece. Tais ideias confirmam a abordagem teórica trazida por lkeda (2008).

\begin{abstract}
Mas, nos vários âmbitos das sociedades, não será sempre a questão política que se explicitará na música, na forma de confissão consciente ou programático-partidária. Muito ao contrário, na maioria das vezes, a música de sentido político resultará da percepção intuitiva da realidade, como uma consciência política apenas potencial (IKEDA, 2008).
\end{abstract}

A música de protesto dos anos sessenta, melhor traduzidas pelas composições de Chico e Vandré, assim como apresentado por lkeda (2008), de certa forma não apoiavam os movimentos que não estivessem ligados a política diretamente partidária. Entre esses movimentos, os

18 Gênero que tem raiz no samba e que propõem o uso de instrumentos que não estão na sua formação.

19 Gênero que descende da Música caipira ou regional e que, assim como o pagode, traz outras formações instrumentais em suas apresentações.

20 Queer, em português excêntrico. Relaciona-se ao povo underground e aos homossexuais. 
que lutam pelo reconhecimento da importância da comunidade afrobrasileira na expansão estrutural e cultural do país.

As propostas de movimentos de esquerda não incluíram os anseios e reinvindicações negras. Essas eram protagonizadas, desde a década de trinta, pela Frente Negra Brasileira, que culminou no Movimento Negro Unificado (MNU). $\bigcirc \mathrm{MNU}$ teve seu ponto alto em algumas ações realizadas nos anos setenta e oitenta. Ações que se transformaram em parte do processo que resultou nas Leis de Diretrizes Básicas (LDBs), que regulam, hoje, muitos direitos das populações afrodescendente. Podemos afirmar que situações de racismo e de preconceito também aconteciam nos partidos de esquerda, tanto pela negação quanto pela omissão. Um exemplo desses fatos é o caso apresentado por Abdias Nascimento, senador da república no governo de Fernando Henrique Cardoso. Nascimento foi fundador do Teatro Experimental do Negro (TEN) e importante ativista que lutou pela democracia racial. Nascimento relata que, na década de cinquenta, criou o Comitê Democrático Afrobrasileiro, que funcionava na mesma sede da União Nacional dos Estudantes (UNE) e do TEN.

$\bigcirc$ grupo fundador insistiu na necessidade do comitê cumprir seu objetivo fundamental: a defesa da população negra em todos os aspectos da realidade do país. E aqui chegamos ao momento culminante: utilizando como escudo a máscara branca dos "radicais" negros, os "radicais brancos" como maioria expulsaram seus três fundadores, Abdias Nascimento, Aguinaldo de Oliveira Camargo e Sebastião Rodrigues Alves. $\bigcirc$ motivo justificador da expulsão: éramos negros racistas! Com a nossa exclusão os "amigos brancos" destruíram mais este esforço no sentido de organizar uma força política independente da comunidade negra. Pois logo que saímos do comitê este morreu de morte natural: para defender a classe operária e os oprimidos de qualquer origem já existia o partido comunista, ao qual aqueles radicais pertenciam (NASCIMENTO, 2002 p. 184).

Através desse relato, percebemos que até mesmo movimentos como a UNE ou o Partido Comunista Brasileiro (PCB) apresentavam dificuldades em se aventurar em lutas que se constituíam como o cotidiano dos ativistas afrodescendentes. Categorizar Abdias Nascimento e seus colegas enquanto "radicais racistas", no entendimento de Abdias (e 
também no meu), era demonstrar que não se reconhecia o direito ao levante do negro em suas lutas, e que, nem o "proletariado"2l nem a "estudantada"22 incluíam a questão racial como um dos maiores problemas que afetavam (e ainda afetam) o crescimento da sociedade brasileira. Um dos resultados dessas ações, ou falta de ações, foi proporcionar que as lutas pelas questões raciais permaneçam acirradas até os dias de hoje, quase setenta anos depois. Apesar das conquistas dos ativistas negros brasileiros é necessário explicar à maioria da sociedade o porquê das cotas raciais nas universidades e o porquê da necessidade do ensino das culturas negras nas escolas. Ainda lemos e ouvimos na imprensa relatos sobre as estatísticas que anunciam os números elevados do genocídio dos jovens negros nas periferias do país. Para os intelectuais "não negros" naquela época, o racismo brasileiro não existia, e em seu lugar existia no Brasil uma "democracia racial", com direitos iguais para brancos e negros.

É fundamental que entendamos que a música de protesto afrobrasileira, desde muito antes, assim como seus movimentos de libertação, buscava um caminho, senão conjunto, no mínimo paralelo ao que se gritava nas ruas contra a ditadura militar. $\bigcirc$ tema era a busca pela afirmação e pelo respeito aos direitos dos negros como cidadãos. No exemplo usado por lkeda (2008), encontramos, já numa poesia muito antiga, a resistência. Essa poesia representaria exatamente o momento em que os escravizados reivindicavam seus espaços e seus momentos de lazer, longe do olho repressor de seus "senhores". ${ }^{23}$

\author{
Dança negro \\ Branco não vem cá \\ Se vier \\ Pau há de levar \\ (Lenira, apud IKEDA, 2018)
}

Em diálogo com Ikeda (2018), apresento, então, o caso do cantor Wilson Simonal, que se localiza "mais para perto" de nossos tempos atuais. Apresento essa abordagem propondo a existência de uma importante dicotomia dentro dessa discussão. Nos anos da ditadura militar no Brasil, Wilson Simonal cantava sua afirmação em tributo a Martin Luther King.

21 Classe trabalhadora.

22 Nome dado aos estudantes que faziam parte das passeatas.

23 Donos dos escravizados. 
Sim sou negro de cor

Meu irmão de minha cor

que te peço é lutar sim

Luta mais

Que a luta está no fim

(SIMONAL, 1967)

Porém, Simonal (1967) não falava apenas sobre o operário, mas sim sobre a pessoa negra, que detinha ainda menos direitos, que estava desdentada e subempregada, e que não tinha direito as vagas das fileiras trabalhistas das ruas (por não ser empregada formalmente). A formação escolar da maioria negra, muitas vezes, se realizava até, no máximo, a conclusão do que hoje chamamos ensino fundamental. operário negro estava desempregado. Quando estava empregado, sendo ele de ideologias políticas de esquerda ou de direita, sempre recebia salários inferiores aos brancos, sempre atuava nos piores cargos do mundo profissional.

Simonal era considerado por muitos como um alienado que não falava contra a ditadura abertamente. Além desses fatos, ainda contatou a polícia em uma situação que envolveu um de seus empregados, o que resultou na prisão e na tortura de um inocente. Por esses motivos, - cantor foi deixado no ostracismo pela mídia e "esculachado" pelos colegas, além de ter sido "guardado na geladeira" até a hora de sua morte. Esse isolamento resultou em um desespero enorme de tentar se redimir com o público. Ao mesmo tempo em que cometeu aquele ato, considerado por mim como uma estupidez com seu empregado, Simonal cantava músicas como Dinguilindingue.

Olha o dinguilindingue

Olha o dinguelindangue

Recompensuê

Arrarrá

Recompensuê

(SIMONAL, 1973)

Essa cantiga, na verdade, é uma cantiga para Exu Mavambo, 24 porém, na época, não foi percebida como tal. Em contrapartida, essa cantiga tradicional foi entendida como uma reinvindicação dos direitos

24 Mavambo é qualidade de Exu, entidade que está entre os Orixás e a humanidade. 
religiosos que estavam sendo reprimidos pela política da ditadura, que impunha o pensamento cristão na "base da porrada". Simonal também trazia, pela boca de Exu, formas de protesto onde se escondiam códigos de luta e resistência da comunidade negra religiosa. Segundo Nascimento (2008), essa comunidade era, e ainda é, uma das formas mais positivas de quilombo.

Quilombismo se estruturava em formas assertivas que tanto podiam estar localizadas no seio da floresta de de difícil acesso que facilitava sua defesa e sua organização econômico-social própria, como também assumiram modelos de organizações permitidas ou toleradas, frequentemente com ostensivas finalidades religiosas (católicas), recreativas, beneficentes, esportivas, culturais ou de auxilio mútuo. Não importam as aparências e os objetivos declarados: fundamentalmente todas elas preencheram uma importante função social para a comunidade negra, desempenhando um papel relevante na sustentação da comunidade africana. (NASCIMENTO, 2008, p,2)

Simonal não era o único a cantar uma música com voz política voltada às comunidades afrobrasileiras. Nas rádios do país, se escutava também outros grupos afrodescendentes, que tentavam, fortemente, promover a integração com cantores como Osvaldo Nunes, Noriel Vilela e o Trio Tincoãs. Todos eram representativos de uma música que possuía ótima qualidade, sob os pontos de vista da melodia, harmonia e ritmo.

\section{A vez e a voz do bonde}

movimento musical do funk, iniciou trazendo mensagens semethantes as ouvidas nos maracatus, lundus, cocos e sambas. Essas manifestações musicais das culturas tradicionais escutavam e faziam reverberar as vozes da população pobre e preta, descendente de pessoas que foram escravizadas e trazidas a força para o Brasil. A linguagem de protesto utilizada hoje em dia pela "juventude do funk", utiliza-se de uma forma "pornográfica" para referir-se aos órgãos sexuais, misturandose com perfumes e bebidas caras. Porém, nem sempre essa linguagem foi assim configurada. 
Nos primeiros momentos do movimento hip hop, no Rio de Janeiro, esse gênero trazia os recados das "gentes das favelas", de seus problemas em relação a violência, causados pela polícia e pelo crime organizado, num lugar onde, ainda na atualidade, "não se sabe bem quem é quem", nem na lei e nem na criminalidade. Se pode observar essa ideia em alguns versos do Rap do Silva, que apresenta uma narrativa baseada em "mais uma tragédia do morro".
Era um domingo de sol
Ele saiu de manhã
Pra jogar seu futebol
Deu uma rosa pra irmã
Deu um beijo nas crianças
Prometeu não demorar
Falou para sua esposa
Que ia voltar pra almoçar
(MC BOB RUM, 2007)

músico apresenta um "cidadão qualquer da favela", que vai para o seu cotidiano, "todo dia fazendo sempre igual", assim como como dizia o poeta: de marmita, trem lotado e "revista da polícia pelo caminho". Naquele fim de semana, ele não sabia que no morro carioca em que ele morava iria "rolar" uma "tragédia grega", na qual ele seria o protagonista do final trágico.
Era trabalhador
Pegava o trem lotado
Tinha boa vizinhança
Era considerado
E todo mundo dizia
Ser um cara maneiro
Outros o criticavam
Porque ele era fanqueiro
(MC BOB RUM, 2007)

O crime do protagonista estava no funk. Se pode traçar um diálogo com essa ideia através do poema Civilização Branca, de Solano Trindade. 
(li num jornal)

crime não estava no homem

Estava na cor de sua pele

(TRINDADE, 1999)

Jogar futebol era prática comum entre os pais e entre os vizinhos do protagonista da canção, porém, ser "fanqueiro" aproximava-o do jovem que estava na "linha da violência". Indumentária marcada pelas anotações das páginas policiais e das "cadernetas de suspeito das regras"25 da Polícia Militar (PM).

Era só mais um Silva

Que a estrela não brilha

Ele era fanqueiro

Mas era pai de familia

(MC BOB RUM, 2007)

Nesses versos, se repete a mensagem do mestre compositor, proferida durante a luta contra a ditadura militar do Brasil: "Morreu na contramão atrapalhando o tráfego" (HOLANDA, 1976). O peão caído do prédio em Construção.

Já o compositor Mc Marcinho, repete na voz de Mc Bob Rum, o refrão do Rap do Silva, porém, utilizando-se de palavras diversas para comunicar discurso semelhante ao de Holanda. $\bigcirc$ cidadão comum, que tem seus dias interrompidos, num evento comum da cidade grande. Segundo Ikeda (2008) "é nesse terreno do ideológico, da luta pelo estabelecimento dos parâmetros, estéticos, técnicas, de significação ou funcionalidades, que as ações culturais são vitualmente políticas" (IKEDA, 2008?).

Porém, a composição, musicalmente simplista, de Bob Rum, não se projetou na "pirâmide social". Não alcançou a classe média, nem tampouco interessou aos políticos de esquerda. Para esses e aqueles, aquela música era proveniente de lugares sem cultura, de pessoas analfabetas, com rimas retas e sem elegância. Lembremos que nem o compositor, nem o produtor, nem os executantes daquelas linhas musicais possuíam o conhecimento das regras de raízes vindas do eurocentrismo, sendo assim, não organizavam suas composições segundo essas regras.

25 Metáfora relativa ao que a PM tem como referência de suspeito, que é sempre relativa à aparência e à indumentária. 
$\bigcirc$ que eles conheciam era o desejo do suingue ${ }^{26}$ para o groove $e^{27}$ dos bailes, a mensagem cifrada e "simplificada" para os ouvidos da "garotada do morro".

A beleza e a elegância do funk se deixava apoiar, unicamente, no flow ${ }^{28}$ apresentado pelas batidas 29 e pelas rimas. Rimas que, muitas vezes, iniciam no tempo da caixa ${ }^{30}$ de James Brown e dos surdos de primeira $^{31}$ das escolas de samba cariocas. Dito de outro modo, no tempo dois, assim como me demonstrou o rapper e poeta Zinho Trindade, na ocasião de uma de suas apresentações em São Paulo.

Porém, "a favela tinha visitas". A Zona Sul carioca se interessou. Era "chique" ir a favela, principalmente, depois da música tocada no Favela Chic, na Republique de Paris, onde a balada 32 "enfiava só porradão33 carioca". A "comunidade" tinha virado cartão postal, com direito a Safari. Movimento que "deve ter sido causado por uma praga", contra o protesto de Cidinho e Doca, que reivindicavam no Rap da Felicidade, a inclusão da comunidade na história do "Rio de Janeiro turístico".

Nunca vi cartão postal

Que me mostrasse uma favela

Só vejo paisagem

Muito linda e muito bela

(CIDINHO; DOCA, 2007)

Porém, ao contrário do que o Rap anunciava, "o turista não ia mais só pra zona sul beber água de coco, ele queria ir pra favela ver o pobre passar o maior sufoco" (CIDINHO; DOCA, 2007). E isso custou muito caro, para a comunidade e também para o funk. Para a comunidade, "ficou ruim", porque para que o turista entrasse, era preciso "pacificar a favela". Assim, instalaram-se nas comunidades as Unidades da Polícia Pacificadora (UPPs), que nada mais são do que quartéis da PM, que deveria, na verdade, proteger os cidadãos cariocas e os turistas.

26 Palavra utilizada em música para referir-se a balanço.

27 Palavra utilizada em música para referir-se a ritmo, levada.

28 Palavra utilizada em música para referir-se a elegbancia e a forma certa de se rimar.

29 Palavra utilizada em música para referir-se aos beats criados pelo DJ.

30 No ritmo do Rock`n Roll, normalmente as batida da caixa de bateria estão no segundo tempo de cada compasso.

31 Surdos de primeira, os mais graves da escola de samba, também tem sua marcação no segundo tempo.

32 Festas e bailes noturnos da juventude.

33 Palavra utilizada em música para referir-se às melhores músicas do Funk.

\section{4}

REV. TULHA, RIBEIRÃO PRETO, v. 6, n. I, pp. 167-193, jan.-jun. 2020 
Não funcionou bem assim. Junto com as UPPs vieram as milícias, herdeiras do Esquadrão da Morte, famosos nos anos sessenta pelo seu grupo de "vigilantes" assassinos. A milícia teve seu primeiro "xeque-mate" mundial apenas na história recente do país. A morte da ativista brasileira Marielle Franco (Presente!) provocou a comunidade internacional, que reivindicou os direitos da pessoa humana.

que "ficou ruim" para o funk, foi que, com o objetivo de aproximar a classe média do morro, o mercado deslocou a linha de protesto contra os problemas locais para o ostracismo e ofereceu em troca o "amor das minissaias e corpões da galera do alto", a oportunidade de se ver um traficante armado de perto. Em contrapartida, as meninas e meninos da classe média trouxeram seus confortos para os bailes do morro e a possibilidade de assistir a propaganda sexual proposta pelas cachorras ${ }^{34}$, tchutchucas ${ }^{35}$ e, principalmente, pelas preparadas ${ }^{36}$ (aquelas que já estavam prontas). Era só "colar em algum bonde firmeza, que estava valendo". Nesse contexto, os versos de Cidinho e Doca "saíram pela culatra".

\author{
Eu só quero é ser feliz \\ Andar tranquilamente na favela onde eu \\ nasci \\ E poder me orgulhar \\ E ter a consciência \\ Que o pobre tem seu lugar \\ (CIDINHO; DOCA, 2007)
}

A favela já não era mais segura para o pobre. Assim como as escolas de samba cariocas, ela tinha sido abduzida pelo mercado. $O$ jovem fanqueiro seguiu seu caminho, imitando os rappers norte-americanos na indumentária e na exposição gratuita de cordões pesados, pulseiras e relógios enormes, em locações de clipes onde multiplicavamse champagne, caviar e biquínis. Esses objetos de desejo se transformam em "sonhos de consumo", ainda que, na maioria dos casos, esses produtos só existam em lugares onde os negros e pobres não tem licença de

34 Palavra utilizada para referir-se às meninas que fazem sexo.

35 Palavra utilizada para referir-se a mulheres jovens que, inclusive, podem ser virgens.

36 Palavra utilizada para referir-se à mulheres que "já vão sabendo que vão ter sexo". Existe a ideia de que elas iam para as festas sem as roupas íntimas, por isto, a utilização do termo preparadas. 
entrada e são, muitas vezes, quando conseguem entrar, seguidos por um segurança "quase disfarçado".

Mano Brown, cantor e principal figura do Racionais Mcs, concorda. Para Brown, "status é um nome que o branco inventou para foder com o preto. Nós não queremos status, queremos viver" (BROWN, 2018). Brown aponta a atitude que, "no final das contas", o jovem periférico optou em seguir: "criar uma fronteira entre o lado de cá e o lado de lá da ponte", referindo-se aos bairros da Zona Sul e a Região Central de SP; estabelecer, do seu lado, um movimento próprio de desenvolvimento humano e cultural.

Assim, "demos de cara" com a Coperifa, o Sarau do Binho, O Espaço Clariô, o Candearte e muitos outros locais e regiões, inclusive no centro da cidade. Ali encontramos o entre outros o Aparelha Luiza. Esse é considerado o primeiro quilombo urbano do Estado de São Paulo. Nesses lugares, a comunidade negra e periférica criou referências culturais. Todos são bem recebidos, inclusive, (claro que com restrições), o "povo do outro lado da ponte". A maioria desses locais são remanescentes dos Pontos de Cultura, projetos do Ministro Cilberto Passos Gil Moreira (Gilberto Gil). Idealizados durante o governo do Presidente Lula da Silva ("Sentiu a diferença?").

Atualmente, nos clipes veiculados nas diferentes mídias, continua se mantendo apenas a ideia das casas e carros chiques, sendo que as pessoas negras foram excluídas do cast contratado. $\bigcirc$ que restou, realmente, foi o funk proibidão ${ }^{38}$, cantado nos bailes que trazem figuras estranhas, como os filhos do funk (lenda urbana que faz alusão as crianças de pais desconhecidos, devido a mãe, durante a música, ter "sentado em vários falos diferentes"). Nos versos, existe alusão, também, a muito sexo pornográfico, ora em momentos extremamente machistas, e ora em outros, "esquisitamente", feministas. Os temas importantes percorrem uma estética que retorna à comunidade negra e uma poesia, ainda simples, mas que aborda temas como o amor e as formas de amar do século XXI.

Que tiro foi esse,

37 Pontos de Cultura foram criados no governo de Lula da Silva, pelo Ministro da Cultura Gilberto Gil e possibilitavam o empreendedorismo dos grupos de cultura popular que não tinham acesso ao mercado.

38 Funk Proibidão é o termo utilizado para referir-se as músicas que só toca nos bailes, não no rádio. A pornografia nos textos do Proibidão é faladas de forma explícita.

\section{6}

REV. TULHA, RIBEIRÃO PRETO, v. 6, n. I, pp. 167-193, jan.-jun. 2020 
Que tiro foi esse que tá um arraso?

(MORONTINI, 2018)

"Não tem ninguém armado...nem vai ter cheiro de pólvora". A expressão "que tiro foi esse" (MORONTINI, 2018), se refere a um "gostoso" ou uma "gostosa" que acaba de chegar na "balada", "fazendo sensação e alarde", como diria Roberto Carlos. A compositora e cantora, ou melhor, Mc, é Jojo Morontinni, antes conhecida como Jojo Toddynho. Jojo é o contrário da estética do mercado brasileiro da música, opulentamente gorda e com seios exagerados e a vista. Usando roupas curtas e apertadas, Jojo traz no clipe, no seu corpo de baile e no cast de figurantes um grupo grande de negros e negras.

Nego do Borel, em Me Solta, já nos 140 BPM, vem "desafiando o baile todo". Em um clipe "pra lá de sexy", devolve a "favela em peso" para a produção. $\bigcirc$ grupo coreográfico se assemelha as pessoas do lugar, proporcionando a sensação de serem figurantes oriundos das comunidades retratadas. É a volta do "negro comum" na "cabeça do funk"39 Tanto Jojo, quanto Borel fazem parte das "descobertas" da cantora Annita, que insiste em "reenraizar" o "batidão" apesar do seu notável sucesso entre as classes médias e alta.

A cantora Iza apresenta no clipe Dona de Mim, um funk melody40, a história de muitas mulheres negras. Essas mulheres são professoras, domésticas, médicas, que saíram das favelas e necessitam "lutar dobrado por dignidade". Atualmente, o funk "desenvolveu”, em função do seu andamento que é tocado em velocidade muito mais acelerada do que em suas abordagens iniciais. Neste mesmo processo, se tornou minimalis$\mathrm{ta}^{41}$, com "agogôs recortados"42 e "levadas em staccato"43, evitando a utilização de notas com alturas definidas, e "dizendo palavras" de forma ainda mais falada, mais agressiva.

39 Palavra utilizada em música para referir-se a música que é ponta do mercado do Hip Hop.

40 Palavra utilizada em música para referir-se a um Funk romântico, um pouco mais lento. $41 \bigcirc$ funk hoje usa cada vez menos notas nos beats, também menos harmonia em compensação mais velocidade.

42 Palavra utilizada em música para referir-se a levada do Congo de Oro (Ritmo do Candomblé), que iniciou a nova fase do Funk e foi sendo recortada e tocada de forma incompleta.

43 Palavra utilizada em música para referir-se a notas curtas, secas e picadas.

\section{7}

REV. TULHA, RIBEIRÃO PRETO, v. 6, n. 1, pp. 167-193, jan.-jun. 2020 
funk nasceu na Zona Sul carioca antes de se deslocar para o subúrbio. Lá era tocado e "dava lucro", com a "galera" das favelas de Copacabana, Vidigal e Rocinha. Ademir (1997), importante disc jockey carioca, faz uma análise de algumas ideias, em depoimento colhido por Hermano Vianna.

As coisas estavam indo muito bem por lá. Os resultados financeiros estavam correspondendo a expectativa. Porém começou a haver falta de liberdade do pessoal que frequentava. Os diretores começaram a pichar (Falar mal de) e a por restrição em tudo. Mas nós íamos levando até que pintou a ideia da direção do Canecão de fazer um show do Roberto Carlos. Era a oportunidade deles para intelectualizar a casa, e eles não iam perde-la, por isso fomos convidados pela direção a acabar com o baile. (ADEMIR, 1997 apud VIANNA, 1997, p 24).

"Intelectualizar a casa", significava retirar os jovens negros que frequentavam os bailes. Além dessa motivação principal, outras também existiam, mas essa era a considerada principal.

No início de seu desenvolvimento, o "funk carioca", organizado pelas "batidas" Miami Bass, trazidas pelo sampler do DJ Marlboro, foi passando por arranjos de tambores da escola de samba. Essas influências, abordadas por Ivo Meireles e Fernandinha Abreu e, posteriormente, pelas "batidas de atabaques" 44 do Congo de Oro ${ }^{45}$, praticados na umbanda carioca, chegaram agora pelas vozes sem beats, como se pode observar no clipe do Mc Bin Laden, intitulado Tá Tranquilo, Ta Favorável. Qualquer menino ou menina com um smartphone poderia elaborar seu próprio clipe e monta-lo em casa com seus "parceiros". "Depois, era só jogar no YouTube e rezar".

44 Ritmos tocados nos atabaques.

45 Ritmo tocado nos Candomblés e Umbandas. 


\section{Conclusão}

Início esta conclusão com um relato de Paulão (1988), discotecário da Equipe Black Power, em depoimento colhido, novamente por Vianna. Nesse depoimento, Paulão tece algumas considerações sobre - Movimento Black Rio, considerado o precursor do Movimento Hip Hop brasileiro. Essa analogia foi realizada durante uma reportagem do Jornal do Brasil, escrita por Lena Frias em dezessete de julho de 1976. Essa reportagem intitulava-se $O$ orgulho (importado) de ser negro no Brasil.

Que eu saiba foi o Jornal do Brasil que inventou o nome Black Rio. Eu nem sei se o meu nome estava ali naquela matéria. Eu nem sei quem é a Lena Frias. Mas o nome da minha equipe era muito forte e, de carona nessa história de Black Rio eu fui parar no DOPS (PAULÃO, apud VIANNA, 1988, p. 27).

O soul de James Brown, de Tim Maia, e o suingue de Jorge Ben (Benjor), que andavam pelos subúrbios cariocas, eram os "aquilombados" que mais atraíam gente jovem para os bailes noturnos, para as "disputas de bairros"46, para 0 namoro dos jovens, para organização de trabalhos de escola durante a semana, ou para "fazer festa só por festejar". Segundo a reportagem de Frias, esses jovens, em sua maioria, não bebiam, não fumavam e não usavam drogas. $\bigcirc$ importante para eles era reforçar o orgutho de ser negro, usar roupas referenciadas pela série televisiva Shaft (com a abertura elegantíssima de Isaac Hayes que contava com arranjos próprios e de Johnny Allen) e assistir (para reproduzir nos bailes) os passos difíceis dançados no Soul Train ${ }^{47}$. Para assistir a série, "a galera toda tinha que ir pra casa de um que tivesse um aparelho de TV", o que "naquelas paradas" era muito raro. O cinema acabara de lançar o filme de Cleópatra Jones. Tamara Dobson, atriz e modelo, atuava como uma agente negra da CIA, recentemente visitada e profundamente admirada pelo atual presidente do Brasil, Jair Bolsonaro (Parece brincadeira!).

46 Brigas de bairros, ou de ruas vizinhas. Esporte da periferia.

47 Soul Train era um programa de televisão que trazia os dançarinos americanos ao palco, para que esses mostrassem aos jovens brasileiros as possibilidades coreográficas para o baile. 
Eu assisti Cleópatra Jones, na ocasião em que o filme foi exibido no "Poeirinha de Piedade", sala de cinema famosa por seu repertório de pornochanchadas ${ }^{48}$, prédio que, futuramente foi alugado pela lgreja Universal do Reino de Deus. Naquela ocasião, eram poucos os negros que tinham acesso aos cinemas. Da mesma forma, frequentei os bailes black, (como nós, os jovens da década de setenta, nos chamávamos). Éramos todos Brau (em referência a James Brown). Não éramos muito diferentes dos jovens dos bailes funk dos dias de hoje.

Em meu tempo, o jovem negro queria se olhar no espelho e ver um jovem negro. As referências estéticas da época obrigavam-nos a alisar os cabelos e a nos portarmos como brancos, caso quiséssemos ocupar alguma vaga de emprego (na maioria, subempregos, que eram as únicas possibilidades oferecidas à população negra da época). Já os fanqueiros, além da autoafirmação sobre a questão racial e da autoestima, lutam por um lugar nas universidades, melhores escolas, trabalhos em igualdade de condições para homens e mulheres, espaços de lazer para as crianças. Dito de outra forma, o jovem negro de hoje não quer "só ser negro", como na minha época. Naquela ocasião, a propaganda midiática e os livros didáticos nos condicionavam a pensar em nós mesmos como feios, desalinhados, burros e deselegantes. $\bigcirc$ jovem de hoje quer igualdade em todos os sentidos. Por essa razão, usa todos os caminhos possíveis para adentrar o mercado, inclusive a música.

Porém, a música de protesto negra, ainda hoje, é recebida com desconfiança pela sociedade. $\bigcirc$ mercado continua buscando ídolos que não se pareçam com o público frequentador das comunidades negras. Além disso, deprecia os gêneros musicais de protesto da música negra, usando termos como lascívia, produção de violência, despudor. Logo em seguida, cria uma figura "não negra" para protagonizar o estilo, apresentando-o como alguém que "descobriu" o gênero na "raiz", transformando-o em uma forma que pode ser considerada culta e interessante para todas as idades e canais de televisão. Enquanto isso, as perseguições nas favelas, o racismo em shoppings, supermercados e espaços de lazer, se cercam de muros. Esses muros são, quase sempre, protegidos pela "polícia especializada em prender pessoas inocentes". Finalizo, então este texto, com uma reflexão de Mano Brown. "Para dar lucro, as casas de shows, assim como as cadeias, precisam estar lotadas..." (BROUN, 2018).

48 Filmes dos anos 70, nos quais eram realizadas comédias com teor sexual. 


\section{Referências}

COMES, Leno Maycon Viana; BOREL, Nego da; PENHA, Rennan da. Me solta - Kondzila, São Paulo: Som Livre, 2018.

HOLANDA, Chico Buarque de. Apesar de você. Compacto Simples. Rio de Janeiro: Polygram Philips, 1970.

HOlAndA, Chico Buarque de. Construção. LP Construção. Rio de Janeiro: Polygram Philips, 1971.

BRASIL. MINC. Oficina Nacional de Elaboração de Politicas Públicas de Cultura Para os Povos Tradicionais de Terreiro. Relatório Final, Brasília, 2012.

PEREIRA, Pedro Paulo Soares (Mano Brown) - Mano Brown, Um Sobrevivente do Inferno - Entrevista - Le Monde Diplomatique - Brasil 2018 - SP. julho 2019.

https://www.youtube.com/watch?v=gMT9cXizDYQ - 20:20 Visita em

CIDINHO; DOCA;MALBORO; SELVA. Rap da Felicidade. Columbia Records - 1994 - RJ

https://www.youtube.com/watch?v=7pD8k2zaLak (visita em 2019).

IZA. Dona de mim - Warner Music Brasil - 2018 https://www.youtube. com/watch? $v=$ FnCfgb_YNE8 (visita em 2019).

IKEDA, Alberto Tsuioshi. Musica Politica e Ideologia: Algumas Considerações. (2001)

RIAS, Lena. Reportagem de Lena Frias (comentada): Jornal do Brasil julho de 1976. Disponivel em: https://zinezerozero.blogspot.com/201 1/05/ os-black-e-reportagem-de-lena-frias.html. Acesso em 2019.

BIN LADEN, Mc. Tá Tranquilo Tá Favorável - KL Produtora 2014 SP. https://www.youtube.com/watch?v=5ab4wKxfHcw 
SILVA, Moises Osmar da (MC Bob Rum). Rap do Silva. Som Livre 1996 RJ. https://www.youtube.com/watch?v=oVO I oCAprCO

NASCIMENTO Abdias. O Quilombismo. Fundação Cultural Palmares, Brasilia, 2002,

Jornal da Música, n 30, 1977.

Um conceito emergente do processo histórico-cultural da população afro-brasileira: Uma proposta do autor aos seus irmãos e irmãs afrodescendentes no Brasil e nas Américas, Il Congresso de Cultura Negra das Américas, Anais... Panamá, 1980.

NASCIMENTO, Elisa Larkin (org). Afrocentricidade: Uma Abordagem Epistemológica Inovadora, Coleção Sankofa, vol IV.

MARONTINNI, Jojo. Que Tiro Foi Esse - VEVO - Brasil - 2017

https://www.youtube.com/watch?v=Qw4uBk7DOa8 2002.

PAULE LECHAT, Noelle Marie. Civitas. Revista de Ciências Sociais,

RIVEIRA, Silvia; BARBER, Kattalin. Silvia Rivera Cusicanqui: "Tenemos que producir pensamiento a partir de lo cotidiano". El salto. Disponível em: https://www.elsaltodiario.com/feminismo-poscolonial/silvia-riveracusicanqui-producir-pensamiento-cotidiano-pensamiento-indigena. Acesso em 01.06 .2019

SANTOS, Silvio Matheus Alves. $\bigcirc$ método da autoetnografia na pesquisa sociológica: atores, perspectivas e desafios. Plural, Revista do Programa de Pós-Graduação em Sociologia da USP, São Paulo, v 24. I, 2017, p. 214-241.

SIMONAL, Wilson; BÔSCOLI, Ronaldo. Tributo a Martin Luther King - Compacto simples, lado A - Gravadora Odeon (1965)

SIMONAL, Wilson; DOMÍNIO POPULAR Dingue Li Dingue Dingue Li Bangue - Album É Bufo no Birrolho Grinza - Philips (1973)

TRINDADE, Solano. O Poeta do Povo - Cantos e Prantos Editora $1969-\mathrm{SP}$ 
VANDRÉ, Geraldo. Caminhando - Festival Nacional de Música - TV Record 1968 - SP 1988.

VIANNA, Hermano. O Mundo Funk Carioca. Jorge Zahar Editor,

\section{Sobre o autor}

Vitor Israel Trindade de Souza (Vitor da Trindade) nasceu em 1956. Artista desde os 12 anos de idade é herdeiro cultural da Familia Solano Trindade, que desde a década de 50 se empenha na manutenção e divulgação da cultura afro-brasileira. Atuou como músico da noite paulistana $e$ arte educador com várias ong e entidades governamentais. Vitor é bacharel em Música Popular pela Faculdade Instituto Tecnológico de Osasco e mestrando em etnomusicologia pelo departamento de música da ECA-USP. Estudou percussão afro-cubana com Dinho Gonçalves na FAP-ARTE, violão e canto popular com Laura Campaner e Consiglia Latorre na ULM-Tom Jobim. Foi professor na Musikschule Schoneberg, em Berlim na Alemanha, eé professor convidado na Landesmusikakademie, Berlin, desde 1998. Tem sete discos próprios gravados, 4 no Brasil, 1 na França e 2 na Alemanha. Já apresentou seu trabalho como professor e artista na Europa, Ásia, África e Américas do Sul e Central.

Recebido em 23/07/2019

Aprovado em 29/06/2020 